Alfonso Escudero

\title{
La actividad literaria chilena en 1924
}

\section{DECLARACION PRELIMINAR}

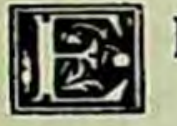

NTRE las sensaciones más desagradables de mi vida de lector, recuerdo especialmente las ocasionadas por la ignorancia desdeñosa que ciertos extranjeros manifiestan sobre literatura chilena.

Un crítico norteamericano. Isaías Goldberg, en su libro sobre La liferatura hispanoamericana. habla hasta de un señor Eguren. que debe ser muy conocido en su barrio. y no dice una palabra de Chile sino para anotar que tal cual poeta pasó por nuestra tierra, como pudo agregar que André Gide, por ejemplo, había pisado alguna vez tierras de Africa.

Ventura García Calderón, que todavia no puede perdonarnos el haberlo obligado a nacer en el valle central de Chile (en Talca), intercala, en sus Semblanzas de América, las de tres peruanos, y de nuestro país no se acuerda sino para regalarle el calificativo de sraza bovinas.

Otro escritor, un gros monsieur Domínici, venezolano que no tiene por qué estar agraviado de los escritores de Santiago. acaso con el propósito de dárselas de entendido. hace algo mucho más feo y perjudicial que el no hablar de chilenos: quiere hacer creer que uno de sus Tronos vacantes habia estado ocupado por nuestro pobre Pedro Antonio González, el 
de las palabrerias huecas. ¡Ni trono ni vacante. señor tropical! O más bien, trono, que. de entre nuestros muertos pudieron merecer Magallanes. Contardo o Pezoa Véliz, antes que ese González; pero que sería absolutamente imposible estimar vacante, viviendo todavia, por la gracia de Dios, la Mistral. Prado. Mondaca y varios otros escritores chilenos dignos de codearse con lo más selecto de las letras hispano-americanas.

Acaso algún día explane la anotación. Por ahora me toca sólo recordar las actividades literarias de 1924.

\section{POESIAS Y VERSOS}

Jorge González Bastias publica su tan esperado segundo libro.

Jorge González, dice el fino cronista nacional Hugo Silva. de Los Tiempos, ses ingénita. Catalmente poeta. Su sensibilidad se expresa en versos de una manera espontánea y natural. y en una forma más pura, más suya. a medida que va viviendo. Y sufriendo... Canta, o llora, el medio en que vive. su río. sus cerros, y la vida sombría y miserable de los hombres que los pueblan. Su Doema de las fierras pobres es un treno desolado por los dolores de una comarca empobrecida por la obra de los esquilmadores administrativos y los jueces terroristas. No es una protesta clamorosa y lírica, con cóleras tempestuosas y arranques víclorhuguescos. Su verso es quedo. silencioso. salurado de la resignación dolorida y fatalista del campesino. Y si hay grandiosidad y elevación en algunos pasajes del poema. surgen de la misma dantesca desolación de las escenas descritas.

Hasta aquí Julio César (Hugo Silva).

Ciertos criticos oficiales recibieron mal la obra de González Bastias. Tal vez tenian sueño. Sin embargo. El poema de las tierras pobres es un bello libro épico-lírico de un buen poeta. saturado de amor al terruño (Maule y sus contornos). animado de un humanitarismo sin vaciedades ni exageraciones ultraprogresistas y que vive alejado de los círculos literarios de la ca- 
pital, junto a un rio a cuya orilla hay barcas recogidas ccomo anhelos dormidos. .

Su dolor es un dolor muy humano. expresado en estrofas algo libres y de un ritmo exquisito.

Y algo curioso. Las stierras pobres,. la montaña cansada. que canta o llora en su poema. son las mismas que vieran días mejores. Pero ya nadie puede volver a ver la hermosura de los días idos, sporque sin alegría. no hay corazones que la sientans.

A pesar de todo, en sus últimas páginas el poeta expresa alguna confianza en el mañana. Y al recordar que la campana está llamando a la gente a la iglesia, añade:

Y una mano que se alza dulce, piadosamente.

bendiciendo, guiando.

y el estremecimiento del que inclina la frente porque ha sentido a Dios y está adorando.

Es una esperanza que renace. $Y$ un buen coronamiento de uno de nuestros mejores volúmenes poéticos del año.

Ciertos críticos han dado sucesor a don Luis Felipe Contardo, el malogrado poeta sacerdote de los Cantos del camino. en la persona de otro sacerdote, poeta y pintor, don Francisco Donoso G.. autor ya de tres volúmenes, el último de los cuales se titula Myrrha.

¿Y si fuera apresurarse demasiado?

En Donoso no es tan fácil hallar ese rocio de emoción espontánea, delicada y comunicativa de que tanto abundaba Contardo. Con lo cual tampoco quiero decir que el joven autor de Myrrha carezca de condiciones. Sus estrofas, de corte variado y de expresión pura y correcta. tienen un suave tinte melancólico encuadrado en un marco sobrio y la elegancia de la educación clásica modificada por la lectura de los renovadores modernos. 
Pablo Neruda (Neftali Reyes, dicen). el poeta de veinte pri. maveras que el año pasado entregaba al público un Crepusculario extraño hasta en el formato. ahora publica Veinte poemas de amor y una canción desesperada.

Un paso atrás, a mi entender. El afán de originalidad le corta las alas al verso. La emoción está ausente. Lo único que sale a recibirnos es un portero de librea revolucionaria (también hay libreas revolucionarias). perito en sutilezas e imágenes que algunas veces son bonitas. pero que no nos convencen del todo.

Carlos Préndez Saldias ha caminado mucho desde el muy lejano punto de partida de su primer libro (1914) hasta el de este año, que es feliz hasta por el titulo: Amaneció nevando.

Tiene aciertos innegables en sus evocaciones de paisaje criollo: pero, sobre todo, en el sentido In memoriam dedicado al poeta Magallanes.

Lineas prometedoras hay en la Voz ferviente. poemas de Roberto Munizaga Aguirre. La señorita María Rosa González (Miss Colombine) escribe su apasionada Samarifana. Una poetisa anónima deja elegantes y láciles Huellas en la nieve. Don Antonio Bórquez Solar hace imprimir La tragedia del General José Miguel Carrera. Un profesor de francés. M. Augusto Lescure, dice en francés Cantos y visiones del camino. volumen que el critico Omer Emeth halló espléndido y hasta heredianos. Oscar Jara Azócar publica Cantos de juventud: Jorge Octavio Flores. La locura de ser; Gerardo Seguel. Hombre de otoño: F. García, Por la senda del dolor: Berta Quezada. Motivos...

Promesas que nadie sabe si se cumplirán algún dia.

De las selecciones que nos vienen dando Eduardo Barrios y Roberto Meza Fuentes por medio de la editorial Nascimento. en 1924 ha salido la de Amado Nervo (Sus mejores poemas). Es. como dije en cierta nota bibliográfica, un ramillete rico en va- 
riedad y más rico aún en calidad, como que es la selección de la obra de un poeta exquisito, concentrado. emotivo. y sobre todo. muy distanciado de los versificadores grandilocuentes que él crucificó sin decirlo, al bautizar un libro suyo con el bello nombre de En voz baja.

Otras selecciones son las de Las mejores poesias para la declamación (Nascimento) y la de Recifaciones escolares hecha por Jorge Guzmán Dinator.

Pero la más importante de las selecciones del año ha sido la voluminosa antologia chilena moderna que Armando Donoso tituló Nuestros poetas.

Comienza con un interesante prólogo donde el critico nos habla de la literatura chilena. desde cuna edad media ni enorme ni delicada.. hasta los que más son valores de mañana que de hoy. Luego siguen las tres partes que dividen la obra. división arbitraria e inexacta. aunque no se puede dejar de reconocer que el segundo periodo (de 1905 a 1920) es, como dice Donoso. el más interesante de la poesía lírica chilena y uno de los más significativos de la literatura americanar.

Es un periodo merecedor de una antologia hecha con más atención que la empleada por Donoso. Y no sólo porque en Nuestros poetas haya nombres sobrantes y nombres olvidados. sino principalmente porque se nota poco cuidado en la selección y copia de las poesias de cada autor. Las notas biográfico-criticas y las referencias tampoco son muy dignas de $\mathrm{Ar}$ mando Donoso.

En definitiva, Nuestros poetas es una obra de aliento y de aciertos en las lineas generales, pero aleada por lalta de mayor esmero en los detalles, que, en obras de esta indole. tienen tanta importancia.

$\mathrm{Y}$ es que Donoso trabaja demasiado en diversos órdenes de cosas, y. es claro, sus libros resultan inferiores a lo que pudiera esperarse. 


\section{NOVELAS. CUENTOS Y OTROS RELATOS}

Un juez rural, el último libro de Pedro Prado, es una obra inclasificable. Es una especie de novela que recuerda el estado del alma y las actividades de cierta época de la vida de su autor, el simpático poeta, novelista, pensador, pintor, arquitecto. gran causeur y hombre bueno que es Pedro Prado. el mejor temperamento artistico y el más respetable de los escritores chilenos del dia. Los Diez, Alsino. Los pájaros errantes, La casa abandonada y sus demás obras lo habian colocado muy alto. Ahora Un juez rural. más ceñida a la realidad que las precedentes. lo hará admirar de mayor número de lectores.

Esteban Solaguren-es decir. Pedro Prado-. padre de buen número de hijos y favorecido por mil ventajas de todo género. vive en una quinta de los alrededores de Santiago. Parece feliz. Pero cierta inquietud intima lo mantiene intranquilo. EI Intendente de la provincia lo nombra juez de paz. Solaguren, a pesar de no haber estudiado leyes. no renuncia. Juzgará en conciencia. Comienza el desempeño de su nuevo cargo. Y Solaguren con sus nervios hiperestesiados y cogido de sla manía de pensar, va resolviendo las querellas del barrio en fallos originales. llenos de saber y de elevación: vagabundea por las cercanías con su amigo el pintor Mozarena. medita, analiza sus menores sentimientos y sensaciones, se intranquiliza cada vez más, duerme poco, renuncia el juzgado, se va a la costa con su Camilia y vuelve a los pocos días más inquieto y preocupado que antes.

Todo ello, en un estilo claro. flexible, de mucho color y movimiento. $\mathrm{Y}$ a trechos, ironias finas. envueltas en una sonrisa delicada. Característica muy principal de la obra, como que corresponde a un período agudo de inquietud intima de su autơr, es también cierta sensación de soledad. que se hace más palpable en las últimas lineas de la obra.

Por otra parte. sin ser ante todo el gran pintor verbal que es Mariano Latorre, tiene, sin embargo, Pedro Prado, a lo lar- 
go de su obra, cuadros, perfiles y escenas de un sabor real muy subido: $y$ hay análisis, como el del cansancio, de una originalidad y precisión admirables.

- -iTan poco estudiado que está nuestro pueblo!-dice el pintor Mozarena en cierto pasaje. Cuando vago por los caminos con mi caja de pinturas, cuando voy por los campos o los pequeños caserios, y observo sin ánimo de observar... todo lo que vislumbro, dentro o fuera de mí, me parece un descubrimiento. No sabes, entonces, qué desprecio tengo por los libros. qué distancia por nuestro pobre arte y por todas las cosas conocidas?.

Después de la lectura de Un juez rural. Daniel de la Vega habría obligado a Mozarena a retirar sus palabras.

Con $U_{n}$ juez rural. Prado, o sea, según el elogio de Alone. el egran pescador de perlas que nunca recoge sus redes en vano. aunque las tire al arroyos. se renueva y se completa cada vez con mayor lelicidad.

¿Durante muchos años todavias. concluye Luis D. Cruz Ocampo. Pedro Prado tendrá el maravilloso privilegio de hacer que su última obra sea la mejor de lodas.

Curioso caso el de la última novela de Augusto Thompson. Pasión y muerfe del cura Deusto. editada en Madrid, es una novela bastante inverosimil y que demuestra en su autor no poca ignorancia de la vida eclesiástica. El lenguaje abunda además en francesismos $\mathrm{y}$ otras incorrecciones; $\mathrm{y}$ aun habria varios otros peros que anotar.

Pero Augusto DHalmar es todo un artista: y sus inverosimilitudes e incorrecciones se olvidan ante ese encanto extraño que le comunican a la obra el interés del drama interno del cura vasco trasladado a Sevilla. el movimiento acertado de escenas y situaciones, la espontaneidad de la concepción artística y un decir flexible y matizado de mil gallardias originales o espigadas en mil campos diversos.

- Parece descuidado-dice Hernán Díaz Arrieta. (Alone)-y hace resonar la más sabia de las orquestas: parece claro y se 
matiza de todas las medias tintas del agua en el crepúsculo: parece primitivo, nitido, infantil. y tiene descomposiciones de luz y serpenteos voluptuosos de bayadera asiática. .

Novela de autor americano con teatro en España. Pasión y inuerte del cura Deusto tenia que hacer recordar otras dos novelas célebres: El embrujo de Sevilla y La gloria de don Ramiro. Pero el chileno Augusto Thompson ( ${ }^{\prime}$ Halmar). menos novelista y aun quizá menos escritor que el uruguayo Carlos Reyles y que el argentino Enrique Rodríguez Larreta, es más artista que cualquiera de ellos, y su obra-no disonaría como la tercera de las unidades de una bella trilogía literaria que hasta ayer estaba incompleta.

Joaquin Ortega Folch. que en 1923 publicó Betsabé. ahora se reconcilia con buen número de lectores. por medio de su novela Una confesión.

Mariano Latorre prefiriria llamarla .Una coqueta.. De una coqueta se trata. en efecto. Es una novela corta. de estilo agradable, de trama sencilla y con sus ribetes de psicológica. Y su autor, un joven de treinta años, que sabe dar interés al relato. defiende una tesis valiente. cuenta a Maupassant y a Chejov entre sus maestros, $y$. sobre todo. que, a pesar de sus errores de procedimiento y lenguaje. parece tener pasta de novelista.

El capitán retirado don Olegario Lazo Baeza se dió a conocer en 1922 con unos Cuentos Militares recibidos con aplauso raro por lo universal y merecido. En 1924 hace editar Nuevos Cuentos militares.

Literariamente ha progresado bastante. Es más concentrado. mejor pintor, de realismo más vigoroso. Casi siempre se hace interesante. Es sobrio. Ha aprendido a dar pinceladas de experto. Pero. como hace notar Ricardo A. Latcham, en general. -nuestros militares están pintados en aspectos no muy honrosos,. Lo cual, después de todo, no es obstáculo para que el ex-capitán Lazo, que tiene facilidad extraordinaria para el relato. los haya escrito tan dignos de leerse en cualquier pais, como 
La última etapa. El paralitico y esa maravilla titulada El padre.

De Eduardo Barrios, el autor de Un perdido y EI hermano asno. aparece en 1924, aunque con lecha del año anterior. las Páginas de un pobre diablo.

Una obra más. compuesta de cuatro relatos, agrupados con el título del que inicia el volúmen. La importancia principal del tal relato consiste en la revelación de un aspecto poco conocido en Barrios, el humorismo. De.lo demás del libro. merece mencionarse Canción. idilio de toques semirománticos.

El escritor chileno residente en Paris y encargado de la critica de libros hispanoamericanos en el Mercure de France. Francisco Contreras, publica La ville merveilleuse. Es una serie de siete relatos independientes y de desenvolvimiento cansado. Un critico parisiense de Nouvelles littéraires la llama essai, no roman. Hacía tiempo que se sabia que La ville merveilleuse sería la primera obra de una serie en que su autor, aficionado tardío al folklore, procuraría utilizar las creencias populares para interpretar la vida de Hispanoamérica, especialmente la de Chile.

Una empresa digna de otra pluma.

El Pbro. don Julio T. Ramirez, el novelista que hace tres años pintó escenas algo tristes alrededor de El rancho. lejos de dormirse bajo la corona ganada en un gran certamen americano. hace editar ahora un libro de cuentos titulado Del mar y la sierra.

Es una obrita simpática, impregnada de buenos sentimientos. de amor a la naturaleza chilena y de honda piedad humana ante los sinsabores de la vida de los campesinos evocados en sus cuentos. Un decir sin artificio sirve de ropaje a una trama sencilla. Pero es una sencillez que concluye por hacerse algo desconcertante, y se desearía que un poco más de complicación viniera a dar más interés al relato.

Y uno piensa en que el poeta don Abel González, prologuista de la obra, acaso tenga razón cuando dice: .Parece que el 
señor Ramirez ha tenido el propósito, no tanto de novelar. como de presentar una serie de cuadros de la naturaleza y de la vida campesina, plenos de fuerte colorido local y animados por la más sincera realidad moral de los personajes que pone en juegos.

El muy ameno memorialista de Como si fuera ayer... el hombre de pluma y de casaca don Emilio Rodriguez Mendoza, exalumno del Colegio de San Agustín. publica, en la Biblioteca Nueva de Madrid, una segunda edición de su novela chilena Santa colonia, obra de un movimiento algo lánguido, pero importante como resurrección de un época.

Otras obras novelescas del año han sido: La bestia hombre. ensayo de ambientes no santos. por Lautaro Yankas (Manuel Soto): Un marino, cuento de Jorge Gustavo Silva. premiado en un certamen de 1923: La casa del dolor. de Julio Kloques Cam pos: La caverna de los murciélagos. fantasia extravagante de un escritor que parece quiere tentar suerte en todos los géneros. por Pedro Sienna (Pérez Cordero); La derrota. por Caupolicán Ponce; La hija de la ciega, por Adollo Urzúa Rozas; Alma ae ofros mundos, por Julia Sáez (Araucana): y Ambición de madre. traducción de una obra inglesa de Effie $A$. Rowlands.

\section{HISTORIA, RECUERDOS Y CRÓNICAS}

Don Nicolás González Errázuriz publica El motin de Figueroa: don Alejandro Rios Valdivia, La misión Lavalle; y el exRector de la Universidad de Chile, don Domingo Amunátegui Solar. un folleto titulado Génesis de la independencia de Chile. y su libro Chile bajo la dominación española (refundición, dedicada é la enseñanza, de dos volúmenes del año anterior).

Un escritor de nombre a edad aún muy temprana. Eugenio Orrego Vicuña, nacido y educado en un hogar de escritores. obtiene a principios del año su título de abogado, y su memoria de prueba es todo un libro de doscientas cincuenta páginas, de 
formato grande y de importancia histórica más grande todavía. Me refiero a El espíritu constitucional de la administración OHiggins, de que ya he hablado. Es una obra escrita con cariño al tema y al héroe, y de interés y mérito tanto mayores. cuanto que el constitucional era el aspecto menos estudiado de la vida de $\mathrm{O}$ Higgins.

Aun hay en 1924 otra obra histórico-crítica de Eugenio Orrego Vicuña: su opúsculo sobre Medina y Harrise. después de cuya lectura el dictado de príncipe de los americanistas huye solo del investigador yanqui para refugiarse junto al sabio chileno don José Toribio Medina.

Otro Orrego, don Augusto Orrego Luco. entrega al público otros dos libros: Notas de viaje y Recuerdos de la Fscuela de Medicina. A juicio del joven y competente crítico Ricardo A. Latcham. Notas de viaje sparece el ocaso de un escritor ilustre.s.

(El doctor Orrego nació en 1848).

En cambio. Recuerdos de la Escuela de Medicina-copio una nota bibliográfica mia de la Revista de la Juventud católica-es un libro amable, interesantísimo, escrito con un cariño seductor y de un estilo que recuerda a los maestros del buen decir.

Sus páginas perpetúan !a memoria de figuras ya lejanas, tan simpáticas e interesantes como la de Lafargue, el cviejecito triste. de fisonomía delicada y melancólica: y las de don Rudolfo Philippi, don Ignacio Domeyko, don Ramón Elguero, y tantas otras que no recuerdo por no citar todo el indice. Pero las que prefiero. son las de los primeros años de la Escuela, y sobre todo, la de Domeyko. el heroico Jegota de los poemas de Mickiewicz.

El libro del doctor Orrego es el mejor homenaje que se podía tributar a la antigua Escuela de Medicina y una de las pocas obras recientes que podríamos presentar satisfechos a la curiosidad de los lectores extranjeros.

Otro libro de recuerdos publicado por un anciano escritor de 
estas tierras, es Tapices viejos, de don Javier Vial Solar. Hay en él páginas interesantes y amenas; pero, desgraciadamente, la afición a las reflexiones innecesarias y cierto airecillo de alabador exagerado temporis acti se puero. hacen que la obra pierda no poco.

Uno de nuestros mejores cronistas de periódico, y para algunos, el mejor. Joaquín Edwards Bello, reúne Crónicas suyas en un volumen de presentación muy pobre.

Aunque recuerda con excesiva frecuencia que él fué quien escribió El roto, hace ya algún tiempo que Edwards Bello no publica novelas. ¿Le hizo caso a don Pedro N. Cruz? En la práctica por lo menos, parece que si. El hecho es que, por hoy. Joaquin Edwards es el cronista incorrecto. desaliñado, inquieto. y a pesar de todo. ameno e interesante. con todas sus paradojas, su danza moderna de ideas despreocupadas. sus imágenes atrevidas. sus descripciones vigorosas y sus remolinos desordenados de anotaciones breves.

$Y$. junto a la gravedad de los editoriales pesados, es entretenedor un periodista hábil y de estilo vivo y decir fácil. que escribe comentarios livianos. como Joaquin Edwards Bello. el ameno cronista de La Nación de Santiago.

Dos obras de notas humoristicas han aparecido en el año: $R e-$ flexiones de un optimista. por César Cascabel (el ingeniero Julio Simón) y La biblioterapia. por Rocesin (el abogado Alberto Herrera Arrau, que bautiza su libro con el titulo del primer capitulo). César Cascabel es más fácil de leer; pero Recesin tiene observaciones y ocurrencias más dignas de recordarse.

-Tal vez algún dia, en quién sabe qué puerto de la Tierra, pero seguramente muy lejos del Valparaíso de mi infancia, yo también iré a sacudir la ceniza de mi pipa al bar de algún Peter Petersen; y solo conmigo mismo y mis recuerdos, veré delante de mi un pequeño soñador desencantado. que sólo para mi no ha envejecido. que después de tantos vagabundeos, nada 
ha visto sino el mundo, y al cual, después de tantas peripecias. nada le ha pasado sino la vidas.

Así reza el epílogo de La sombra del humo en el espejo. de Augusto Thompson. $Y$ es un párralo muy representativo de Thompson, el Pierre Loti chileno, el extraño Augusto D $\mathrm{Hal}$ mar. desterrado voluntario del Chile de sus primeros años, viajero impenitente por muchos países de la tierra. fatalista, gran poseur y gran temperamento artístico. supuesto descendiente de piratas noruegos, ssoñador desencantado. y eterno sufridor de una nostalgia de no se sabe qué.

Ese es Augusto D'Halmar. autor de Juana Lucero. La lámpara en el molino. Nirvana y Pasión y muerte del cura Deusto: escritor de tantas páginas mitad francesas mitad castellanas, incorrectas hasta el lujo: y. sin embargo, tan cargadas de un perfume raro compuesto de mil flores exóticas cogidas por la mano experta de un artista con aire de iniciado en sabidurias esotéricas.

Ese es DHalmar, que ahora completa ciertas visiones de Nirvana, con La sombra del humo en el espejo. visiones del Egipto. la India. Grecia. Italia y otros lugares idealizados para él por la lejanía del recuerdo.

(Una nola de la página del copyright. dice que tla traducción francesa de este libro la firmó Francis de Miomandre. gran amigo de $D^{\prime}$ Halmar).

\section{INVESTIGACIÓN, CRITICA LITERARIA Y FILOLOGIA}

El sabio antropólogo e ingeniero inglés residente en nuestro país desde hace poco menos de cuarenta años, don Ricardo E. Latcham. miembro único en Chile del Royal Anthropological Institute of Great Britain and Ireland, regala al público lector dos obras más: un folleto en que, contra opiniones sostenidas hasta el día. prueba la existencia de la propiedad en el antiguo imperio de los Incas; y un volumen sobre La organización social y las creencias religiosas de los antiguos Araucanos 
(tirada aparte de las Publicaciones del Museo de Etnología y Antropologia de Chile, t. III).

El libro sobre los antiguos Araucanos es una interesantisima obra de más de seiscientas páginas de formato grande y de una importancia tal. que casi todas sus sabias conclusiones son. como las del folleto sobre los Incas, verdaderos descubrimienlos.

$\mathrm{Y}$ es porque, ya sea por una u otra causa, las investigaciones precedentes se habrian enredado en no pocos errores. En cambio, el señor Latcham. sabio de fama tanto en América como en Europa. tiene una preparación excepcional para tales estudios $y$ ha vivido en contacto intimo con los araucanos varios años de observación directa. Así, nadie mejor que él, que ahora prepara una refulación de los errores de la teoría totémica de Freud, podia escribir la obra sobre los antiguos Araucanos.

Aunque no todas descubrimientos, recordaré, callando importantes detalles, algunas de las irrefutables conclusiones del sabio investigador anglochileno: cal llegar los españoles a Chile. los indios del país estaban organizados por su sistema totémico. . totemismo que no era de origen incaico: sheredaban el tótem y el apellido por línea femenina : e el apellido se deriva del tótem»: el tótem entre los araucanos no era sinónimo con el antepasado común de quien el grupo tolémico suponía descender. sino que era un sér con quien éste habia formado una alianza: : el sistema social se hallaba en un período de transición>: los cambios originados por la conquista española concluyeron con el totemismo y afianzaron da posición del padre como jefe de la familias: sla religión de los araucanos,- - y no por eso eran ateos- cera el culto de los antepasados, sin que reconocieran ninguna deidad,: el pillán no era otra cosa que el espiritu del cantepasado fundador del respectivo linajes. etc. (Págs. 595-596).

En definitiva. La organización social y las creencias religiosas de los antiguos Araucanos (que el autor ha extractado y adaptado para público menos especialista. en el semanario inglés de Valparaíso The South Pacific Mcill, con el titulo de The 
Romance of Chilean Ethnology), sin pertenecer a la literatura en su acepción restringida. es uno de los mejores libros chilenos del año.

Otro sabio europeo chilenizado, el filólogo alemán don Rodolfo Lenz, también publica dos folletos de interés; Estudio sobre los indios de Chile y La reforma de la gramática. importante resumen este último, en ciertos puntos, de su gran obra sobre La oración y sus partes. que prologó y editó R. Menéndez pidal en Madrid, hace cinco años (1920).

Por su parte, la Universidad de Chile reune en un volumen las siete Conferencias que el profesor de filologia de la Universidad Central de Madrid, don Américo Castro, dió en Santiago a fines de 1923. en la primera de las cuales hace sobre el señor Lenz. entre otros, estos elogios: .El Dr. Lenz es una de las personalidades más notables en el dominio de la filología románicas: y ces el primer investigador que hace la aplicación de la fonética a problemas estrictamente filológicos, .

El estudio biográfico-critico sobre El licenciado Pedro de Oña, que don Enrique Matta Vial nunca quiso publicar en vida. tiene fuera de otros títulos de valia, la de demostrar que. como dice Omer Emeth (es un francés nada amigo de los españoles quien lo dice), cel pasado americano no es tan negro como algunos lo pintan : o, limitándonos a nuestro pais, que a fines del siglo XVI no estaba Chile envuelto en las tinieblas intelectuales que los histo:iadores suelen suponer.

Prueba: el Arauco domado, de Oña. Porque, aunque el poema sea tan poco apetitoso de leer como es. Oña. patriarca de la literatura chilena y aun americana, habia alcanzado la suficiente instrucción para escribir entre sus veinle y veinticinco primaveras, un poema de la extensión y alardes eruditos del Arauco domado.

Don Miguel Luis Amunátegui Reyes, autor de muchas obras 


\section{La acfividad literaria chilena en 1924}

de investigación lingüistica, entrega al público el primer tomo de Observaciones y enmiendas a un Diccionario. aplicables también a otros. Es una crítica excelente. facilitada por los progresos de treinta años, del Diccionario manual que escribió en 1893 otro lingüista chileno. el sacerdote salesiano don Camilo Ortúzar.

El subdirector de la Biblioteca Nacional, don Ramón A. Laval, hace imprimir. con el titulo de Paremiología chilena, su discurso de ingreso a la Academia. en tanto que don Ricardo Dávila Silva abogaba en el suyo por la resurrección de la fábula y de la epopeya. Pero el más comentado de los discursos de ingreso a la Academia impresos en 1924. Tué el del docto P. Raimundo Morales. franciscano. que habló nada menos que de La decadencia del arte de escribir.

Y ahora. los títulos de los tres libros escritos para la enseñanza: Estética liferaria (edición de Herder). por el humanista Pbro, don Guillermo Jünemann. del Seminario de Concepción: Idioma patrio. conforme a los programas del cuarto año de humanidades, por don Eduardo Solar Correa: y Refórica y poéíca, por don Julio Sienzalas, del Seminario de Valparaiso.

\section{TEATRO}

-Rico, casi espléndido,-escribe Eugenio Orrego Vicuña en cierta revista - ha sido el año teatral de 1924. no sólo por la variedad-que ha habido para todos los gustos-sino también en cuanto a valia. Muchas compañias pasaron por los teatros. Pero lo que por ahora nos interesa son solamente las obras dramáticas estrenadas o impresas por autores nuestros.

Y entonces sí que el juicio de Orrego no puede dejar de ser severo: .El teatro nacional --dice- ha continuado languideciendo... Las causas son las mismas de siempre: falta de elementos buenos, carencia de ensayos, de cuidado en la presentación y selección de obras, de repertorio y dirección. Bührle. actor que cuenta con muchas simpatías en el público. hizo un esfuer- 
zo simpático y... fracasó por las razones apuntadas. Su com. pañia alcanzó a estrenar Los ciegos ven. comedia muy bien escrita, de Matias Soto Aguilar, que marcó un éxito..

Otra compañia estrenó. con éxito trambién. Más fuerte que el amor. por la señorita Lidia Boza. El conocido N. Yáñez Silva hizo representar dos traducciones del francés: In vino veritas y Tierra inhumana.

Agrega Orrego Vicuña que, durante el año, se han estrenado, con resultado vario. diversos sainetes y revistas de actualidad nacional que han logrado mantenerse en el cartel.

Pero aún falta mencionar lo mejor, la notable pieza en un acto. titulada Tragedia interior. original del ya tantas veces citado escritor don Eugenio Orrego Vicuña y que estrenó en Santiago y ha prometido dar a conocer. incorporándola a su repertorio, en sus próximas giras por Europa y América, el maravilloso actor español don Enrique Borrás.

Del mismo Eugenio Orrego Vicuña, por el momento. aparte de otras actuaciones y a pesar de su juventud. el mejor y el que más promete de los dramaturgos nacionales, es también la adaptación chilena que de Le maître de son coeur de Paul Raynal. se estrenó en 1923 y apareció impresa en 1924. con el nombre de El amo de su alma. Es la presentación en escena del problema de la fuerza de la amistad ante el amor. Omer Emeth, a pesar de no creer en amos de su alma, y de encontrar algo inverosimiles ciertos pasajes. pasa por sobre escepticismos y pretendidas inverosimilitudes y se deja apasionar con una decisión que hace más palpable. dice el critico. -el triunfo del arte.

Otras obras de arte escénico impresas durante el año han sido El consejo de guerra. por el joven poeta Gustavo Campaña Gandarillas; los muy graciosos, ya que no delicados. sainetes de Pedro J. Malbrán. Los dos quesos de Balta Marín. El día de los inocentes. El arreglo de Washington. Las diez de úlfima. La guerra de don Ladislao y Los muertos mandan; y la ter- 
cera edición de los monólogos de Ernesto Córdoba Parraguez titulados Don Tránsito Canales.

\section{MISCELANEA}

Nuestro sabio don José Toribio Medina sigue como siempre luchando con sus años y publicando libros. De 1924 son la magnifica Cartografia hispano colonial de Chile. Escritores hispano-americanos celebrados por Lope de Vega en el cLaureı de Apolo, y Cantos XVIII y XIX de .Armas antárticas, de Juan Miramontes y Zuazola. con anotaciones.

Otro erudito de valer, don Luis Riso Patrón, da feliz término a una obra de muchos años de labor. su gran Diccionario geográfico de Chile, que comprende 28.215 nombres, distribuídos en cerca de mil páginas de formato grande y letra pequeñita. Los datos hablan solos.

Pedro Prado, asesorado por un grupo de intelectuales amigos. con motivo del movimiento regenerador del 5 de Setiembre. sale un momento de su jardin interior y redacta a la ligera, escondido tras el seudónimo de $\operatorname{Los} X$. ciertas generosas Bases para un nuevo Gobierno y un nuevo Parlamento.

El avanzado escritor chileno residente en Paris. Vicente Huidobro. lanza en francés un folleto titulado Finis Britanniae.

Don Maximiliano Salas Marchán. educacionista distinguido. escribe sobre Las tendencias actuales de la educación norteamericana; y don Abrahám Vera Yanáttiz demuestra la Labor educacional (de Chile) en Arica.

El Pbro. don Alejandro Vicuña P. reune artículos con el titulo de Por la justicia y por la paz; y otro presbitero. don Julio Restat. habla de La existencia de Dios ante la filosofia y las ciencias. y suscita corla pero animada polémica. con sus conferencias sóbre La bancarrota de la evolución.

Mencionaré finalmente los tilulos de otras obras: Historia de las doctrinas económicas en América y en especial en Chile. por el político y economista don Guillermo Subercaseaux: La cuestión social. por Francisco Olgiati, traducción del italiano: La 
evolución inglesa y el régimen parlamentario. por Teodoberto Alvarez: la segunda edición del Voyage en France. por el profesor don Francisco Zapata Lillo: Lamujer. por doña Rosa Prats de Ortúzar: El gobierno de don Bautista Saavedra, por Rigoberto Paredes; El espiritismo. El divorcio. un Manual de apologética premiado por la Universidad de Chile y la cuarta edición (la primera creo que es de 1909) de un Diario de viaje. por el laborioso publicista salesiano don Bernardo Gentilini, que no pasa año en que no publique uno o varios libros: Frutos de mi huerto y En soledad, recopilación de arliculos del Pbro. don Nataniel Eastman: y Legislación social de Chile, por los señores Moisés Poblete Troncoso y Oscar Alvarez Andrews. miembro de la Oficina del Trabajo.

\section{OTRAS ACTIVIDADES LITERARIAS. LAS REVISTAS.}

El proyecto irrealizado de erigirle un monumento al poela Magallanes, originó en la prensa una polémica larga y triste. Resultado. El monumento quedó sin erigir: y Tótila Albert. el escultor chileno-alemán a quien se encomendara la obra, regresó a su rincón berlinés, acaso para no volver más a Chile.

La Sociedad de Conferencias literarias ha continuado su obra. Recordaremos la conferencia de Pedro Prado (el 4 de Abril). que charló con la maestría que le es propia sobre su gran amigo el poeta Magallanes: y la de doña Amanda Pinto de Labarca Hubertson acerca de Selma Lagerlöl.

En la Universidad Católica hubo. entre otros cursos libres. conferencias literarias de importancia, como las que, sobre literatura rrancesa moderna, daba cada semana el Pbro. don Emilio Vaïsse (Omer Emeth). que rayó siempre a gran altura sobre sus ya muy decaidas notas bibliográficas de El Mercurio y tuvo constantemente un auditorio de más de quinientas personas.

En la Universidad de Chile, el profesor de la Sorbona. $M$. paul Hazard. ocupó durante tres meses, - cito sus palabrasune chaire de civilisation française. con una asistencia de más 
- menos trescientos oyentes capables de saisir toutes les nuances $d u$ français.

La joven y ya floreciente Universidad de Concepción tuvo. a su vez. su centro de extensión universitaria donde hablaron. entre otros. Pedro Prado sobre Magallanes y el doctor Carlos Charlín Correa sobre Pasteur: y su circulo de lecturas. donde hubo charlas tales como la de don Enrique Molina sobre Mahatma Gandhi de Romain Rolland. y la del talentoso critico literario don Luis D. Cruz Ocampo. sobre El banquefe de Platón.

Otras conferencias merecedoras de recuerdo en estas líneas. son la de Ricardo A. Latcham. sobre la vida colonial en Chile: la de M. Henri Hoppenot. de la Legación Trancesa. sobre Paul Claudel. Marcel Proust y Paul Valéry: la de don Eugenio Orrego Vicuña sobre Sienkiewicz: la de Pedro Prado sobre su obra $U n$ juez rural: las de don Agustin Nieto Caballero. colombiano. sobre educación; la de don Julio Vicuña Cifuentes sobre Camoens; la de don Ricardo Cox Méndez sobre el Quijote y Cervantes, etc.

$Y$ antes de cerrar e! párrafo, algunos renglones para nuestras revistas.

Educación pierde con el cambio de su primer nombre por el de Cultura, La Revista Chilena de Historia y Geografia (que ha publicado dos magnificos homenajes a don Enrique Matta Vial y a don José Toribio Medina). La Revista Católica, los Anales de la Universidad de Chile y la Revista de Educación Nacional continúan viviendo. Rodó muere definitivamente. La Revista Chilena hace meses no sale.

En cambio. la Revista de la Juventud Católica da pasos de criatura ya orientada: The South Pacific Mail progresa: y aparecen otras revistas nuevas, algunas. muy insignificantes, como La Pensée Française y Agonal: pero una, de tanta importancia y de vida tan vigorosa. que, desde el primer número. fué una de las principales revistas cientifico-literarias con que cuenta hoy el habla castellana.

Me refiero a Atenea. de la Universidad de Concepción. 
IX. LA DERDIDA DEL AÑO: MANUEL MAGALLANES MOURE

Habia nacido en La Serena en Noviembre de 1878.

Comenzó su carrera literaria en el famoso grupo de la revista Pluma y Lápiz. En 1902 publicó su primer libro de versos. Facefas; y en 1904. el segundo. Mafices. prologado por el poeta colombiano Isaias Gamboa. Uno y otro denotan una evolución lenta de un romanticismo mitigado hacia un modernismo discreto.

Pero las que podriamos llamar por excelencia sus obras, vienen más larde. La jornada es de 1910. y La casa junto al mar. de 1918. Finalmente. Florilegio. editado en Costa Rica y prologado por Pedro Prado. reune. en una selección acerfada lo mejor de su labor poética.

Era la suya una poesía sencilla. concentrada. sin artificios. sincera. poesia silenciosa. como de cuerda con sordina. Una especie de vago panteismo solia asomar en sus estrofas. La emoción se trasmitia sin esfuerzo, de alma a alma. Y era una emoción de recogimiento. suave. sin dejar de ser varonil. $Y$ aunque algunas veces su poesia pareciera. como alguien ha insinuado. destinada a decirse al oído de la mujer amada. nunca el sensualismo manchó sus líneas de artista de delicadeza exquisita.

Pero Magallanes Moure. hombre de vasta ilustración artistica. no fué poeta solamente.

Fué periodista. Por los años de 1902 y 1903 edifaba la revista Chile Ilustrado. $\mathrm{Y}$ en diversas épocas de su vida colaboró en numerosas publicaciones de Europa y América. Tenia especial aptitud y predilección para la critica de arte.

Fué pintor. $Y$ el salón oficial de 1919 premió una tela suya.

Escribió para el teatro, y fué nada menos que Borrás quien le estrenó en 1912 su pieza La bafalla. Publicó un libro de cuentos. cuentos de poeta. con sus habituales tintes de romanficismo discreto. Tenian por titulo Qué es amor.

Fué miembro de un partido político. director o presidente o 
mero miembro de varios centros literarios, y. por algún tiempo. alcalde de San Bernardo desde 1905. Pero él no era para esas ocupaciones de actividad. Su temperamento de hombre de silencio. que lo fué confinando cada dia más en una melancolia inquietante. no avenia con la bulla, ni mucho menos-alma buena como la que más, aunque sin conservar las creencias católicas de sus primeros años-toleraba claudicaciones en aras de banderias.

Años hacía que Magallanes, alejándose cada dia más del bullicio de la capital. se habia retirado definitivamente a San Bernardo. Y alli vivió. entre los suyos. largos años de aislamiento voluntario. Llegó, dicen. hasta la precaución de quitar el timbre a la puerta de su casa. para que los curiosos no fueran a importunarlo en su retiro. Su gran amigo Pedro Prado. que tanto bueno del poeta ha recordado en su conferencia de 1924, habia escrito antes en el prólogo de Florilegio:

¿Manuel Magallanes Moure. un hombre más bien alto que mediano. siempre vestido de negro; con su enorme y combada frente plácida. y. hasta ayer, poseedor de una grande y serena barba negra; con sus largos pasos silenciosos. su bondadosa atención. la lugaz chispa de ironia de sus ojos pardos y pequeños, su reir callado, sus lrases vagas y breves. siempre envueltas en humo de cigarro. deja una impresión confusa de quiefud o de misantropia. Tarde, sólo al conocerlo intimamente. sabes que todo aquello es dolor callado...

Más que otros solitarios, este poeta es un sér esencialmente contemplativo. No tiene ni ejerce profesión o trabajo alguno. A veces, por largos intervalos, escribe. Pasa después cinco o seis meses en plena Cordillera de los Andes, en EI Melocotón. un lugarejo perdido al amor de las aguas despeñadas del Maipo. en un valle tan angosto. metido entre tan enormes montañas. que el dia es tres horas más breve. y eterna la noche. toda rumor y solemnidad.

Hombre modesto. acaso, como dice alguien, sla mayor prueba de modestia que (Magallanes) pudo dar, la encontramos en el viaje que hizo a Europa. Se fué calladamente a fines de 1921. 
Viajó, observó y. un buen dia, un año después, lo vimos nuevamente recorrer con su paso lento las tranquilas calles de San Bernardo... Trajo una serie de apuntes e impresiones interesantes. pero no se preocupó de darlos a la prensa; apenas si, por amistad, yo conseguí que me diera un trabajo para Educación. el único articulo que publicó referente a su Viajes. (Gmo. Rojas Carrasco, en Cultura, N. ${ }^{\circ} 1$ ).

- Como los artistas superiores. dice Ricardo A. Latcham. al igual que Contardo. Mondaca. Gabriela Mistral y otros apolonidas ilustres de nuestra tierra, la obra de Magallanes aparece muy condensada,. La selección de Florilegio bastaría para su nombre.

Escribió poco, pero de lo mejor que puede presentar la literatura hispano-americana moderna. $Y$ es que Magallanes, escribe otro poeta. Daniel de la Vega, .dejaba que el tiempo esfumara un poco las lineas de sus impresiones; en el recuerdo. los elementos dispersos se iban armonizando hasta quedar. al fin. el cuadro depurado de detalles inútiles y terminado. antes que el poeta tomara la pluma..

Murió el 19 de Enero de 1924.

.Su vida, añade Daniel de la Vega. fué un puema más?.

Lástima que el monumento que a raíz de su ida se le pensó erigir. se haya hecho humo en medio de palabras inútiles e incidentes tristes de recordar.

\section{OTROS ESCRITORES MUERTOS}

Manuel J. Vega,-Fué escritor y diplomático. Nació en 1845. en Ancud. Concluídas sus humanidades en el Seminario de su ciudad natal. en 1867 se vino a Santiago y se dedicó al periodismo. Colaboró en varias publicaciones. sobre todo en La Libertad de los Arteaga Alemparte y en El Mercurio de Valparaiso. En 1872 se trasladó a París, siempre dedicado a la prensa. colaboró eficazmente en el Diccionario biográfico americano, de Cortés, y no volvió a Chile sino en 1876. para seguir como antes en el periodismo. Inicióse en la carrera di- 
plomática acompañando en la Legación chilena de Colombia al poeta Soffia.

Fué un escritor de gran cultura y pluma diestra. pero que. como tantos otros, no dejó libros dignos de su nombre.

Joaquin Rodriguez Bravo.-Nació en 1852. Fué escritor y abogado. Escribió varios libros. Recordaré especialmente sus volúmenes sobre el Congreso de 1882, sobre Lastarria y sobre Balmaceda.

Había viajado y poseía una gran ilustración. Dicen que conversaba admirablemente. $Y$ esa fué la última de las actividades que le fué permitido desarrollar en la ceguera de los postreros años de su vida.

Aliro Oyarzún.-Era uno de los representantes de la generación joven. Fué el fundador y el director de una de las muchas revistas literarias que han nacido con el santo propósito de borrar pecados de incultura. Pero, antes del segundo número, Dyonisos ya había muerto. Y su fundador desaparecía poco después a los veintisiete años.

Raimundo Echeverria Larrazábal.-Habia nacido en San Javier en 1897. Dicen que no le gustaba frecuentar centros literarios, y que. como tanto joven de los de su edad. era un escéptico convencido. Escribió versos que salieron en diversas publicaciones o no salieron. y murió en San José de Maipo sin haber dado a la imprenta ningún libro.

Julio Munizaga Ossandón.-Era de Vicūia, donde habia nacido en 1888. Fundó y dirigió la revista Penumbras. Colaboró en muchas publicaciones nacionales o extranjeras. En 1914 publicó su primero y único libro. Las rufas ilusorias. versos de tendencias parnasianas. y fué de los premiados en los grandes Juegos Florales que revelaron a Grabriela Mistral. Más tarde se fué a Punta Arenas, donde ejerció su profesión de abogado. fundó y redactó la revista Mireya y fué el alma de la vida li- 
teraria de la ciudad más austral del continente. Hace poco una enfermedad lo devolvió a Santiago. Debía no volver a salir.

Gustavo Balmaceda Valdés.--Fué el marido de Teresa Wilms Montt. Cultivó la novela. Una muerte triste puso fin a su vida desgraciada.

Daniel Solorza Barros.-Con decir que era un estudiante agustino. ya se ha dicho que era ignorado en los circulos literarios del pais. Sin embargo. los que como yo lo conocimos desde niño y vimos los grandes progresos de sus últimos años. sabemos que era una verdadera esperanza de las letras patrias. Su alma rica en emociones delicadas. su imaginación viva y poderosa y su gran laboriosidad. unida a un admirable dominio del verso (de todo lo cual hablaré más extensamente dentro de poco): hacen de su muerte una desgracia.

Habia nacido en Quinamávida. lugarcito de la provincia de Linares. Vestia el hábito agustino desde 1914. En Abril de 1923 había partido a Europa a concluir sus estudios. No volvería a Chile. Murió en Roma. a los veintiséis años de edad. el 20 de Junio de 1924.

Y con este recuerdo al amigo de tantos años. pongo punto final a mi tercera reseña de las actividades literarias del año en Chile.

Santiago de Chile. Febrero de 1925.

ALFONSO ESCUDERO. agustino. 